\title{
Evaluation of Salt Tolerance during the Seed Germination Stage of Five Varieties of Vicia sativa
}

\author{
Zhao Hejing1, Wu Rulin¹, Liu Zhiguo', Zhongkuan Liu², Liu Gui-Xia ${ }^{1}$
}

10.18805/LRF-648

\begin{abstract}
Background: Common vetch (Vicia sativa L.) is a legume that is widely used as pasture, silage and livestock feed. However, the area of secondary saline-alkali land throughout the world has been increasing, resulting to lower crop yields. Therefore, high-yielding common vetch varieties with good tolerance to salt must be identified.

Methods: Salt tolerance during the seed germination stage of five common vetch varieties was assessed using gray correlation, standard deviation coefficient allocation weighted method and membership function value.

Result: Seedling growth characteristics were significantly reduced by increased salt concentration. Notably, while the seed germination potential of the varieties decreased significantly at $0.9 \%$ salt concentration, excluding that of $333 \mathrm{~A}$, these decreased values for germination potential were still more than $50 \%$ higher than that of the control. Based on gray correlation methods and membership function values, varieties were graded according to salt tolerance, in which 22216 was the best, followed by Sujian 3, 7504, and 1586, while $333 \mathrm{~A}$ was the worst.
\end{abstract}

Key words: Germination index, Gray correlation methods, Saline-alkaline tolerance, Seed germination, Vicia sativa L.

\section{INTRODUCTION}

Saline-alkali soils are widely distributed throughout the world and are found in arid and semi-arid regions and in alluvial plains and river basins in many coastal areas. In China, approximately 99 million hectares of soil are saline-alkali (Wang, 1993). However, in recent years, the area of secondary saline-alkali lands in irrigated areas in China has been increasing, with some reaching 50\% (Dong and Zhao, 1998). One of these affected lands is the Nandagang area of Cangzhou, which is located in the alluvial plain of Bohai Bay, it is more prominent to soil salinization, which results to low crop yields and limited varietal options. Since soil salinization has always been an important factor that restricts the development of local agriculture, assessment of crop salt tolerance, which will allow for the selection and utilization of better performance and more adapted species or varieties, is important. In particular, the choice of cold-type salt-tolerant plant varieties that can be used as green manure crops in autumn and winter might contribute to the rational development and utilization of saline-alkali land resources.

Common vetch (Vicia sativa L.) is an annual herbaceous legume that is widely used as green manure, pasture, silage, hay and livestock feed grain. It is a cool-season crop that is native to western Asia and the Mediterranean coast of Europe (Wang, 2004). In recent years, many studies have been carried out on common vetches in China, most of which have mainly focused on yield traits and the mixed sowing mode and its effects on the yield and quality of mixed crops (Han et al., 2013; Wang, 2004) . While there have been a number of reports on salt and alkali stress, only one indicator of biomass change after germination or saline-alkali soil stress has been studied (Zhang, 2010). Reports on some legume species revealed that different genotypes or cultivars
${ }^{1}$ College of Life Science, Hebei University, Baoding, 071002, China. ${ }^{2}$ Institute of Agro-resources and Environment, Hebei Academy of Agriculture and Forestry Sciences, Shijiazhuang 050051, China.

Corresponding Author: Liu Gui-Xia, College of Life Science, Hebei University, Baoding, 071002, China. Email: liuguixia1971@163.com

How to cite this article: Zhao, H.J., Wu, R.L., Liu, Z.G., Liu, Z.K. and Liu, G.X. (2021). Evaluation of Salt Tolerance during the Seed Germination Stage of Five Varieties of Vicia sativa. Legume Research. DOI: 10.18805/LRF-648.

Submitted: 20-08-2021 Accepted: 04-12-2021 Online: 09-02-2022

exhibited different salt-tolerance (Khan, 2018; Trisha et al., 2021). Therefore, we screened common vetch varieties with good agronomic traits for their ability to tolerate salt stress.

\section{MATERIALS AND METHODS}

The seeds of five common vetch varieties with good agronomic traits, namely 22216, 333A, 1586, 7504 and Sujian 3 , were selected from the rich germplasm collection of the experimental station of the Wuwei District of Gansu Academy of Agricultural Sciences. The mean seed mass of the 100 -grain was $7.5,6.1,7.7,8.0$ and $9.2 \mathrm{~g}$, respectively.

\section{Test design method}

Two neutral $\left(\mathrm{NaCl}\right.$ and $\left.\mathrm{Na}_{2} \mathrm{SO}_{4}\right)$ and alkali $\left(\mathrm{NaHCO}_{3}\right.$ and $\mathrm{Na}_{2} \mathrm{CO}_{3}$ ) salts were selected based on the salt components of the salt-alkaline soils in Bohai Bay. And a mixture of $\mathrm{NaCl}$, $\mathrm{Na}_{2} \mathrm{SO}_{4}, \mathrm{NaHCO}_{3}$ and $\mathrm{Na}_{2} \mathrm{CO}_{3}$ in a proportion of 5:3:1:1 with $\mathrm{pH}$ ranging from 8.85-9.06 was used to simulated salt and alkali soil conditions. Treatments consisted of five mixed double-salt solution levels $(0.3,0.6,0.9,1.2$ and $1.5 \%$, v:v). 
Seeds were rinsed with $75 \%$ alcohol for $30 \mathrm{~s}$, treated with $1 \%$ sodium hypochlorite for $10 \mathrm{~min}$ and then washed $5-8$ times with sterile deionized water. Fifty seeds were placed per dish and then incubated at $25^{\circ} \mathrm{C}$ for $12 \mathrm{~d}$. The number of germinated seeds was recorded every day, while the germination potential was calculated on the $5^{\text {th }}$ day after germination. Each treatment was repeated three times.

\section{Measurement and calculation method}

The radicle and plumule lengths were measured using a scale and measurements from 30 seedlings per treatment (10 replicates per treatment) were averaged. The dry weight of the seedlings was measured after being kept in a hot air oven at $80^{\circ} \mathrm{C}$ for $48 \mathrm{~h}$. The germination potential, germination rate, relative germination rate, germination index, relative germination index, vigor index and relative vigor index were calculated using the following formula:

(1) Germination potential $(\%)=$ $\frac{\text { Number of germinated seeds on } 5^{\text {th }} \text { day }}{\text { Number of seeds kept for germination }} \times 100 \%$

(2) Germination rate $=$

$$
\frac{\text { Number of germinated seeds }}{\text { Number of seeds kept for germination }} \times 100 \%
$$

(3) Relative germination rate $(\%)=$

$$
\frac{\text { Germination rate of treated seeds }}{\text { Germination rate of control) }} \times 100 \%
$$

(4) Vigor index $(G i)=\sum \frac{G t}{D t}$

\section{Where}

Gt represents the number of seeds per day and Dt represents the day of the seeds germinated.

(5) Relative vigor index $(\%)=$

$$
\frac{\text { Vigor index of the treated seeds }}{\text { Vigor index of the control }} \times 100
$$

(6) Vitality index $=$ Seedling dry weight $\times$ Vigor index

(7) Relative vitality index (\%) =

Vitality index of the salt concentration treatment

$$
\text { Vitality index of the control }
$$

\section{Statistical analysis}

Data were processed and analyzed using Excel and SPSS 21.0 and SPSS was used for one-way ANOVA and statistical significance was determined as $p<0.05$.

The subordinate function values were calculated for the 11 salt-tolerant indicators measured by the five $V$. sativa varieties. The calculation formula was as follows:

$$
\begin{gathered}
X_{(\mathrm{u} 1)}=\frac{\left(X_{i j}-X_{j \min }\right)}{\left(X_{j \max }-X_{j \min }\right)} \\
X_{(\mathrm{U} 2)}=1-\frac{\left(X_{i j}-X_{j \min }\right)}{\left(X_{j \max }-X_{j \min }\right)}=\frac{\left(X_{j \max }-X_{i j}\right)}{\left(X_{j \max }-X_{j \min }\right)}
\end{gathered}
$$

Where

$\mathrm{X}_{\mathrm{ij}}$ was the measured value of the $\mathrm{j}$ index of the $\mathrm{i}$ variety; $X_{\text {jmax }}$ was the maximum measured value of the $j$ index of each variety; and $X_{j \min }$ was the minimum measured value of the $\mathrm{j}$ index of each variety. The membership function value should be calculated using equation 1 if the measured index is positively correlated with the salt tolerance of the plant and with equation 2 if the measured index is negatively correlated with the salt tolerance of the plant. The salt tolerance of each variety was assessed by comparing the average values of the specific membership function values of each index. The smaller the average value indicated the weaker the salt and alkali resistance of the plant.

The multi-index standard deviation coefficient weighting method, which was based on the relative importance (weight) of each comprehensive index, was used to obtain a comprehensive evaluation value of the salt tolerance of the material. According to the previously calculated membership function value, the standard deviation coefficient $V_{j}$, the weight coefficient of each index, $\omega_{\mathrm{j}}$ and the comprehensive evaluation value of each variety were obtained using the following equations:

$$
\begin{gathered}
V_{j}=\frac{\sum_{(i=1)}^{n}\left(X_{i j}-X_{j}\right)^{2}}{X_{j}} \\
\omega_{j}=\frac{V_{j}}{\sum_{(j=1)}^{n} V_{j}} \\
D=\sum_{(j=1)}^{n}\left(X_{j}^{*} \omega_{j}\right)
\end{gathered}
$$

A comprehensive evaluation analysis using the grey correlation method was also performed. Each test variety was represented by the letter $X$, while the character was represented by the letter $K$. The value of each test variety $X$ at trait $K$ constituted the comparison sequence $X_{i}$, whereas $X_{0}$ took the optimal value of each indicator as a reference variety. The correlation coefficient was calculated according to equation 6 and the weighted correlation degree was calculated using equation 8 , where $\rho$ is the resolution coefficient, $\rho=0.5$.

$$
\zeta_{i(k)}=\frac{\underset{i}{\min \min }\left|X_{0}(k)-X_{i}(k)\right|+\rho \underset{i}{\max \max }\left|X_{0}(k)-X_{i}(k)\right|}{\left|X_{0}(k)-X_{i}(k)\right|+\rho \underset{i}{\max \max _{k}}\left|X_{0}(k)-X_{i}(k)\right|}
$$

$\left|X_{0}(k)-X_{i}(k)\right|$ is the absolute difference, denoted as $\Delta i(k)$.

$$
\Delta \mathrm{i}(\mathrm{k})=\left|\mathrm{X}_{0}(\mathrm{k})-\mathrm{X}_{\mathrm{i}}(\mathrm{k})\right|
$$

$$
\text { Weighted relevance: } \gamma_{I}^{\prime}=\sum_{(k=1)}^{n} \omega_{i(k)} \zeta_{i(k)}
$$

$$
\text { Equal weight association: } \gamma_{i}=\frac{1}{n} \sum_{(k=1)}^{n} \zeta i(k)
$$

$$
\text { Weight coefficient: } \omega i=\frac{\gamma_{i}}{\sum_{(k=1)}^{n} \gamma_{i}}
$$




\section{RESULTS AND DISCUSSION}

\section{Effect of salt stress on seed germination}

\section{Germination potential}

The germination potential of each variety was significantly reduced under salt stress $(p<0.001)$ and decreased significantly with increasing salt concentration (Table 1). At $0.3 \%$ salt treatment, no significant difference among some varieties (1586, 7504 and Sujian 3) was observed. Moreover, the difference in the germination potential of some varieties (22216 and 1586 ) under $0.3 \%$ and $0.6 \%$ salt treatment was not significant. Interestingly, while the differences in germination rates and potential were significant at higher salt levels, especially at concentrations over $0.9 \%$ and although the germination potential of all varieties decreased significantly, the germination potential of 22216 , Sujian 3 , 7504 and 1586 were still more than $50 \%$ of that of the control at $0.9 \%$ salt treatment. This is in accordance with the results reported by Zhang Dongjie, wherein he found that the common vetch variety Ximu 324 had high salt tolerance. Moreover, Zhang reported that at salt concentrations of $0.6 \%$ and below, the germination rate and germination potential were not significantly reduced; whereas at concentrations higher than $0.9 \%$, the seed germination potential was decreased and germination took longer periods.

Different varieties of the same species can have significantly different characteristics. Unfortunately, existing research on the salt and alkali tolerance of common vetch seeds during the germination period involves only a few varieties. In this study, we found significant $(p<0.01)$ differences in germination rates and potential among different varieties at the same salt concentration. However, there was no significant difference in germination potential between 22216 and Sujian 3, except at $0.9 \%$ salt concentration. Moreover, 333A consistently had significantly lower germination potential compared to those of the other varieties.

\section{Germination rate and relative germination rate}

The germination rate and relative germination rate in response to salt stress are shown in Table 2. Salt stress significantly affected the germination and relative germination rates of each variety ( $p<0.001$ for both). However, there was no significant difference in the germination rate and relative germination rate between the control and $0.3 \%$ salt treatment groups. Moreover, at salt concentrations above $0.6 \%$, the germination rate $(p<0.01)$ and relative germination rate $(p<0.001)$ decreased significantly with increase in salt levels. Similarly, the relative germination rate of each variety decreased as salt concentration increased. Notably, variety 22216 had the highest relative germination rate while $333 \mathrm{~A}$ had the lowest.

At the same salt concentration, the germination rate and relative germination rate of different varieties differed significantly $(p<0.001)$. Interestingly, at $0.9 \%$ salt concentration, all five varieties had relative germination above $50 \%$. When the salt concentration reached $1.2 \%$, the relative germination rates of 22216 and Sujian 3 were still

Table 1: Effects of salt stress on seed germination potential of five Vicia sativa varieties.

\begin{tabular}{|c|c|c|c|c|c|c|c|}
\hline \multirow{2}{*}{ Measurement index } & \multirow{2}{*}{ Variety } & \multicolumn{6}{|c|}{ Salt concentration (\%) } \\
\hline & & $0(\mathrm{CK})$ & 0.3 & 0.6 & 0.9 & 1.2 & 1.5 \\
\hline \multirow[t]{5}{*}{ Germination potential (\%) } & 22216 & $86.7 \pm 3^{\mathrm{Aa}}$ & $76.0 \pm 5^{\mathrm{Ab}}$ & $70.7 \pm 4^{\mathrm{Ab}}$ & $65.3 \pm 3^{\mathrm{Ac}}$ & $37.3 \pm 5^{\mathrm{Ad}}$ & $17.3 \pm 2^{\mathrm{Ae}}$ \\
\hline & $333 \mathrm{~A}$ & $48.0 \pm 4^{\mathrm{Ca}}$ & $38.7 \pm 3^{\mathrm{Db}}$ & $30.7 \pm 2^{\mathrm{cc}}$ & $20.0 \pm 6^{\mathrm{Dd}}$ & $13.3 \pm 4^{\mathrm{Ce}}$ & $8.0 \pm 1^{\mathrm{cf}}$ \\
\hline & 1586 & $50.7 \pm 6^{\mathrm{Ca}}$ & $45.3 \pm 2^{\mathrm{Cab}}$ & $38.7 \pm 3^{\mathrm{Bb}}$ & $30.0 \pm 3^{c c}$ & $19.3 \pm 2^{\mathrm{Bd}}$ & $11.3 \pm 1^{\mathrm{Be}}$ \\
\hline & 7504 & $60.0 \pm 7^{\mathrm{Ba}}$ & $58.7 \pm 5^{\mathrm{Ba}}$ & $44.0 \pm 5^{\mathrm{Bb}}$ & $40.0 \pm 5^{\mathrm{Bb}}$ & $22.7 \pm 3^{\mathrm{BC}}$ & $16.0 \pm 2^{\mathrm{AC}}$ \\
\hline & Sujian 3 & $81.3 \pm 4^{\mathrm{Aa}}$ & $74.7 \pm 7^{\mathrm{Aa}}$ & $64.0 \pm 3^{A b}$ & $45.3 \pm 2^{\mathrm{Bc}}$ & $36.0 \pm 1^{\mathrm{Ad}}$ & $17.3 \pm 1^{\mathrm{Ae}}$ \\
\hline
\end{tabular}

Note: Different small letters in the same array show significant differences among different concentrations for the same variety; different capital letters in the same column show significant differences among different varieties at the same salt concentration $(p<0.05)$.

Table 2: Effects of salt stress on germination rate and relative germination rate of five Vicia sativa varieties.

\begin{tabular}{|c|c|c|c|c|c|c|c|}
\hline \multirow{2}{*}{ Measurement index } & \multirow{2}{*}{ Variety } & \multicolumn{6}{|c|}{ Salt concentration (\%) } \\
\hline & & $0(\mathrm{CK})$ & 0.3 & 0.6 & 0.9 & 1.2 & 1.5 \\
\hline \multirow[t]{5}{*}{ Germination rate $\%$} & 22216 & $92.0 \pm 4^{\mathrm{Aab}}$ & $86.7 \pm 2^{\mathrm{Ab}}$ & $82.7 \pm 2^{\mathrm{Ab}}$ & $74.7 \pm 6^{\mathrm{Ac}}$ & $46.7 \pm 5^{\mathrm{Ad}}$ & $29.3 \pm 2^{\mathrm{Ae}}$ \\
\hline & $333 \mathrm{~A}$ & $61.3 \pm 5^{\mathrm{Ca}}$ & $54.7 \pm 6^{\mathrm{Da}}$ & $42.7 \pm 2^{\mathrm{Db}}$ & $36.0 \pm 7^{\mathrm{Dc}}$ & $24.0 \pm 2^{\mathrm{Cd}}$ & $16.0 \pm 3^{c e}$ \\
\hline & 1586 & $66.7 \pm 2^{\mathrm{Ca}}$ & $60.0 \pm 3^{\mathrm{Ca}}$ & $52.0 \pm 3^{\mathrm{cb}}$ & $49.3 \pm 3^{\mathrm{cb}}$ & $32.0 \pm 1^{\mathrm{Bc}}$ & $21.3 \pm 2^{\mathrm{BC}}$ \\
\hline & 7504 & $74.7 \pm 6^{\mathrm{Ba}}$ & $72.0 \pm 2^{\mathrm{Ba}}$ & $56.0 \pm 5^{\mathrm{cb}}$ & $49.3 \pm 4^{\mathrm{Cb}}$ & $30.7 \pm 3^{\mathrm{Bc}}$ & $28.0 \pm 1^{A C}$ \\
\hline & Sujian 3 & $88.0 \pm 6^{\mathrm{Aa}}$ & $86.7 \pm 7^{\mathrm{Aa}}$ & $64.0 \pm 4^{\mathrm{Bb}}$ & $57.3 \pm 4^{\mathrm{Bb}}$ & $49.3 \pm 5^{\mathrm{Ac}}$ & $28.0 \pm 4^{\mathrm{AC}}$ \\
\hline \multirow[t]{5}{*}{ Relative germination rate $\%$} & 22216 & $100.0 \pm 0^{\mathrm{Aa}}$ & $94.2 \pm 5^{\mathrm{Aa}}$ & $89.9 \pm 5^{\mathrm{Aab}}$ & $81.2 \pm 4^{\mathrm{Ab}}$ & $50.7 \pm 5^{\mathrm{Ac}}$ & $31.9 \pm 2^{\mathrm{BC}}$ \\
\hline & $333 \mathrm{~A}$ & $100.0 \pm 0^{\mathrm{Aa}}$ & $89.1 \pm 3^{\mathrm{Ba}}$ & $69.6 \pm 3^{\mathrm{cb}}$ & $58.7 \pm 6^{\mathrm{Dbc}}$ & $39.1 \pm 6^{\mathrm{Cc}}$ & $26.1 \pm 2^{\mathrm{Co}}$ \\
\hline & 1586 & $100.0 \pm 0^{\mathrm{Aa}}$ & $90.0 \pm 4^{\mathrm{Ba}}$ & $78.0 \pm 3^{\mathrm{Bb}}$ & $74.3 \pm 7^{\mathrm{Bb}}$ & $48.0 \pm 4^{\mathrm{Bc}}$ & $32.0 \pm 3^{\mathrm{BC}}$ \\
\hline & 7504 & $100.0 \pm 0^{\mathrm{Aa}}$ & $96.4 \pm 5^{\mathrm{Aa}}$ & $75.0 \pm 5^{\mathrm{Bb}}$ & $66.1 \pm 3^{\mathrm{cb}}$ & $41.1 \pm 4^{\mathrm{Cc}}$ & $37.5 \pm 4^{\mathrm{AC}}$ \\
\hline & Sujian 3 & $100.0 \pm 0^{\mathrm{Aa}}$ & $98.5 \pm 6^{\mathrm{Aa}}$ & $72.7 \pm 4^{\mathrm{BCb}}$ & $65.2 \pm 5^{\mathrm{Cbc}}$ & $56.1 \pm 3^{\mathrm{AC}}$ & $37.9 \pm 5^{\mathrm{Ac}}$ \\
\hline
\end{tabular}


higher than $50 \%$, but the difference between their germination rates was small. In contrast, the germination and relative germination rates of $333 \mathrm{~A}$ at each salt concentration were significantly lower than that of the other varieties.

\section{Seed germination index}

The germination and relative germination indices in response to salt stress are shown in Table 3 . The germination index of each variety was significantly different at different salt levels $(p<0.001)$ and decreased with increasing salt concentration. The same trends were observed for the relative germination indices of 22216, Sujian 3 and $333 \mathrm{~A}$ and of 1586 and 7504. Moreover, except for 1586 and 7504 , no significant change in relative germination index was observed at $0.3 \%$ salt concentration $(p>0.05)$. All varieties were significantly different at the other salt concentrations $(p<0.05)$. The difference in the germination index and relative germination index of different varieties at the same concentration was extremely significant $(p<0.001)$. The difference between the germination index of 22216 and Sujian 3 was small. 1586 is similar to that of 7504 and the germination index of $333 \mathrm{~A}$ at each concentration was significantly lower than that of the other varieties.

\section{Effects of salt stress on radicle and plumule length}

We found that radicle and plumule lengths were not affected $(p>0.05)$ by $V$. sativa variety, but salt stress significantly affected radicle and plumule lengths $(p<0.01)$, as both were significantly reduced with increasing salt concentration (Fig 1). While radicle and plumule lengths were not significantly affected by $0.3 \%$ salt, these were significantly reduced in all varieties at higher levels of salinity $(>0.6 \%)$, indicating that the growth of radicles and plumules of the five varieties of $V$. sativa were inhibited at higher salt concentrations. Except at $0.3 \%$ and $0.6 \%$ salt concentrations, in which the radicle and plumule lengths of variety $333 \mathrm{~A}$ were significantly lower than those of other varieties, no significant difference in lengths were observed under salt stress treatment during seed germination.

Effects of salt stress on radicle and plumule dry weight At the same salt concentration, the radicle and plumule weights of different varieties were not significantly different

Table 3: Effects of salt stress on vigor index and relative vigor index of five Vicia sativa varieties.

\begin{tabular}{|c|c|c|c|c|c|c|c|}
\hline \multirow{2}{*}{ Measurement index } & \multirow{2}{*}{ Variety } & \multicolumn{6}{|c|}{ Salt concentration (\%) } \\
\hline & & $0(\mathrm{CK})$ & 0.3 & 0.6 & 0.9 & 1.2 & 1.5 \\
\hline \multirow[t]{5}{*}{ Vigor index } & 22216 & $72.1 \pm 3^{\mathrm{Aa}}$ & $61.4 \pm 3^{\mathrm{Ab}}$ & $43.8 \pm 6^{\mathrm{Ac}}$ & $33.7 \pm 2^{\mathrm{Ad}}$ & $25.7 \pm 2^{\mathrm{Ae}}$ & $8.3 \pm 2^{\mathrm{Af}}$ \\
\hline & $333 \mathrm{~A}$ & $31.6 \pm 2^{\mathrm{Ca}}$ & $25.7 \pm 4^{\mathrm{Db}}$ & $17.0 \pm 5^{\mathrm{Cc}}$ & $13.8 \pm 1^{\mathrm{Cc}}$ & $7.1 \pm 2^{\mathrm{Cd}}$ & $3.4 \pm 1^{\mathrm{Ce}}$ \\
\hline & 1586 & $36.6 \pm 1^{\mathrm{Ca}}$ & $33.4 \pm 5^{\mathrm{Cab}}$ & $28.2 \pm 4^{\mathrm{Bb}}$ & $20.6 \pm 3^{\mathrm{Bc}}$ & $12.4 \pm 1^{\mathrm{Bd}}$ & $7.6 \pm 2^{\mathrm{Be}}$ \\
\hline & 7504 & $38.8 \pm 3^{\mathrm{Ca}}$ & $35.9 \pm 3^{\text {Cab }}$ & $29.6 \pm 5^{\mathrm{Bb}}$ & $22.7 \pm 4^{\mathrm{Bc}}$ & $15.5 \pm 4^{\mathrm{Bd}}$ & $6.6 \pm 1^{\mathrm{Be}}$ \\
\hline & Sujian 3 & $62.5 \pm 4^{\mathrm{Ba}}$ & $51.6 \pm 1^{\mathrm{Bb}}$ & $39.5 \pm 3^{\mathrm{Ac}}$ & $33.3 \pm 2^{A c}$ & $25.4 \pm 2^{\mathrm{Ad}}$ & $10.7 \pm 2^{\mathrm{Ae}}$ \\
\hline \multirow[t]{5}{*}{ Relative vigor index \% } & 22216 & $100.0 \pm 0^{\mathrm{Aa}}$ & $85.2 \pm 3^{\mathrm{Bb}}$ & $60.7 \pm 3^{\mathrm{Bc}}$ & $46.7 \pm 5^{\mathrm{Bd}}$ & $35.6 \pm 6^{\mathrm{Be}}$ & $11.4 \pm 2^{\mathrm{Cf}}$ \\
\hline & $333 \mathrm{~A}$ & $100.0 \pm 0^{A a}$ & $81.4 \pm 5^{\mathrm{Bb}}$ & $53.8 \pm 4^{\mathrm{cc}}$ & $43.8 \pm 3^{\mathrm{Bd}}$ & $22.4 \pm 4^{\mathrm{Ce}}$ & $10.7 \pm 2^{\mathrm{Cf}}$ \\
\hline & 1586 & $100.0 \pm 0^{A a}$ & $92.2 \pm 6^{\mathrm{Aa}}$ & $77.9 \pm 3^{\mathrm{Ab}}$ & $56.7 \pm 2^{A C}$ & $34.1 \pm 5^{\mathrm{Bd}}$ & $21.1 \pm 3^{\mathrm{Ae}}$ \\
\hline & 7504 & $100.0 \pm 0^{\mathrm{Aa}}$ & $92.5 \pm 7^{\mathrm{Aa}}$ & $76.1 \pm 5^{\mathrm{Ab}}$ & $58.4 \pm 3^{\mathrm{Ac}}$ & $39.8 \pm 7^{\mathrm{Ad}}$ & $16.9 \pm 4^{\mathrm{Be}}$ \\
\hline & Sujian 3 & $100.0 \pm 0^{A a}$ & $82.6 \pm 4^{\mathrm{Bb}}$ & $63.2 \pm 4^{\mathrm{Bc}}$ & $53.2 \pm 5^{\mathrm{Ad}}$ & $40.6 \pm 8^{\mathrm{Ae}}$ & $17.1 \pm 3^{\mathrm{Bf}}$ \\
\hline
\end{tabular}

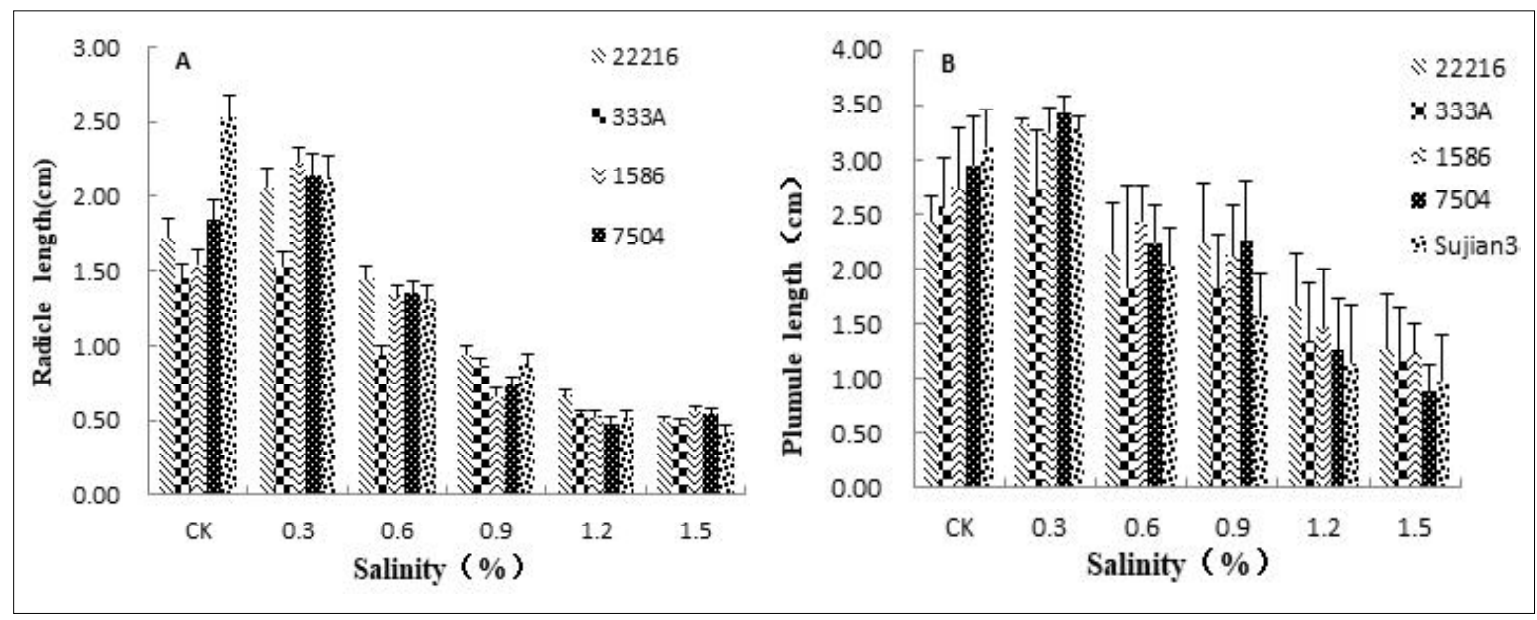

Fig 1: Effects of six different concentrations of salt on radical $(A)$ and plumule $(B)$ lengths of five Vicia sativa cultivars, after $12 \mathrm{~d}$. Each value is the mean of three independent samples. 
Evaluation of Salt Tolerance during the Seed Germination Stage of Five Varieties of Vicia sativa

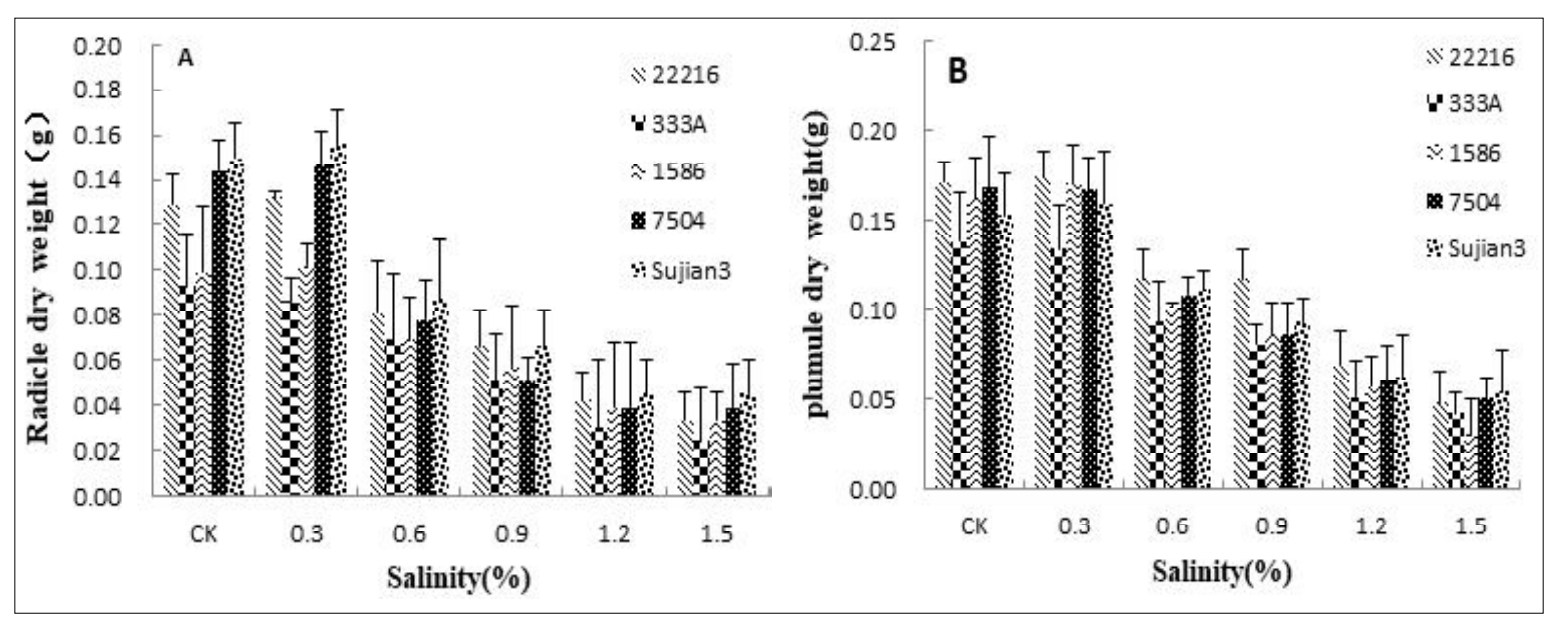

Fig 2: Effects of six different concentrations of salt on the radicle $(A)$ and plumule $(B)$ dry weights of five Vicia sativa cultivars, after $12 \mathrm{~d}$. Each value is the mean of three independent samples.

( $p>0.05)$. In contrast, the radicle and plumule weights of the same variety were significantly different $(p<0.01)$ across salt concentrations. Fig 2 showed similar change trends in the radical and plumule dry weight of each variety, although the weight decreased significantly with increasing salt concentration; at $0.3 \%$ salt concentration, the dry weights of all varieties were not significantly different from that of the control. However, dry weight decreased significantly at higher salt levels $(>0.6 \%)$. Aside from that, root dry weights of 22216, Sujian 3 and 7504 at $0.3 \%$ salt concentration, were higher than those of the control, 1586 and 333A. Consistently, the values obtained from varieties 1586 and $333 \mathrm{~A}$ at each concentration were significantly lower than that of the other varieties.

\section{Evaluation of salt tolerance of five varieties of $\boldsymbol{V}$. sativa} during germination using three different methods

The comparison of salt tolerance among plants or varieties is usually carried out by comprehensive index evaluation. However, it is difficult to evaluate salt using just a single indicator. Thus, it is important to select an appropriate method for the evaluation of salt tolerance in plants (Wang et al. 2016; Liang et al. 2017). In this study, the salt tolerance of common vetch during the seed germination period was comprehensively evaluated using the membership function method (Table 4), multi-index standard deviation coefficient weighting method (Table 5) and gray correlation degree method (Table 6). Similar results were obtained from the membership function and the gray correlation degree methods, whereas those of the multi-index standard deviation coefficient weighting method were slightly different. In that, the order of Sujian 3 and 7504 were switched. Upon further evaluation of the results, we found that the difference between 7504 and Sujian 3 was small, probably because of the similar salt tolerance of the two varieties during the seed germination period. Still, all three evaluation methods showed that in terms of salt tolerance, variety 22216 was better than the other varieties, while $333 \mathrm{~A}$ showed relatively poor salt tolerance.
Table 4: Mean membership function value and rank for different indexes of five Vicia sativa varieties.

\begin{tabular}{lcc}
\hline Variety & Mean function mean & Rank \\
\hline 22216 & 0.5216 & 1 \\
$333 \mathrm{~A}$ & 0.4876 & 5 \\
1586 & 0.4978 & 4 \\
7504 & 0.5005 & 3 \\
Sujian 3 & 0.5012 & 2 \\
\hline
\end{tabular}

Table 5: Evaluation multi-index standard deviation coefficient (D) of five varieties.

\begin{tabular}{lcc}
\hline Variety & Comprehensive evaluation of D value & Rank \\
\hline 22216 & 0.5197 & 1 \\
$333 \mathrm{~A}$ & 0.4779 & 5 \\
1586 & 0.4916 & 4 \\
7504 & 0.5029 & 2 \\
Sujian 3 & 0.4940 & 3 \\
\hline
\end{tabular}

Table 6: Equal weight relevancy value and grey weighted related degree value of each indicator.

\begin{tabular}{lcccc}
\hline Variety & $\begin{array}{c}\text { Equal weight } \\
\text { correlation }\end{array}$ & Rank & $\begin{array}{c}\text { Weighted } \\
\text { relevance }\end{array}$ & Rank \\
\hline 22216 & 0.9564 & 1 & 0.9552 & 1 \\
$333 \mathrm{~A}$ & 0.5448 & 5 & 0.5661 & 5 \\
1586 & 0.6423 & 4 & 0.6699 & 4 \\
7504 & 0.7181 & 3 & 0.7442 & 3 \\
Sujian 3 & 0.8549 & 2 & 0.8636 & 2 \\
\hline
\end{tabular}

Comparing the results from these three methods with our findings on germination characteristics and early embryo growth, we determined the gray correlation method and the membership function method as the more suitable methods for salt tolerance analysis and this is in agreement with the findings of Liang et al. Based on the salt stress simulation test and the growth of alfalfa on different soil contents in the field, Liang et al. considered the gray correlation method as 
the more suitable method for the evaluation of salt tolerance in different alfalfa varieties. Moreover, Wang et al. considered that the gray correlation analysis method is simple and could objectively reflect the comprehensive performance of many traits of the tested alfalfa under salt stress.

\section{CONCLUSION}

The germination and relative germination rates of each variety significantly decreased with as salt concentration increased. The relative germination rate of 22216 was higher, while that of $333 \mathrm{~A}$ was lower. At $0.9 \%$ salt concentration, the relative germination rates of the five varieties in this study were above $50 \%$, with variety 22216 having $81.2 \%$ germination. Aside from this, under salt stress, the radicle and plumule of each variety were not significantly different. Notably, a low salt concentration $(0.3 \%)$ could promote early growth of the radicle and plumule, while a high salt concentration (>0.6\%) could inhibit seed germination and early embryo growth.

In conclusion, during the germination stage, ability of variety 22216 to tolerate salt stress was the best, while that of $333 \mathrm{~A}$ was the worst. Our study suggests that the gray correlation method and the membership function method were more suitable for salt tolerance analysis of different varieties or species.

\section{ACKNOWLEDGEMENT}

This work was supported by the Hebei Grass Industry Innovation team of the Modern Agricultural Industry Technology System (HBCT2018050204) and by the Key Research and Development Project of Hebei Province (20327508D).

Conflicts of interest: None.

\section{REFERENCES}

Dong, X.X, Zhao, S.H. (1998). Physiological responses of tall fescue to salt stress. Pratacultural Science. 1: 10-14.

Han, M., Zhang, H.L., Guo, S.S., Cao, W.D., Liu, X.L. (2013). Germplasm evaluation for yield in Vicia sativa L. Crops. 4: 1-4, 11.

Khan, F. (2018). Salinity stress phenotyping for soybean (Glycine max L.) for Middle East Asia. Legume Research. 41(4): 551-556.

Liang, X., Qi, Y., Lin,Y.J., Cao, W.D., Liu, Z.K., Liu, G.X. (2017). Comprehensive evaluation on salinity performance of 10 alfalfa varieties by comprehensive index and gray correlation methods. Crops. (04):44-49.

Trisha, S., Kumar, S.A., Shailesh, K. (2021). Cross-tolerance physiology of chickpea (Cicer arietinum L.) genotypes under combined salinity and high temperature stress condition. Legume Research. 44(10): 1144-1151.

Wang, C., Chen, J.B., Pang, Z.L., Li, N., Dong, H., Li, D. (2016). The Response and Screening of Germplasm Tolerant to Mixed Saline-Alkali Stress in Sweet Sorghum. Crops. 56-61.

Wang, L. (2004). Application of the analysis of gray relation grade to synthetic evaluation of Vetch varieties. Journal of Sichuan Grassland. 3: 14-16.

Wang, Z, Zhu, S.Q., Yu, R.P. (1993). Chinese saline soil. Beijing: Science Press. 15(5): 325-344.

Zhang, D. (2010). The stress effect of salt on the germination of Vicia sativa L. Heilongjiang Animal Science and Veterinary Medicine. 10(1):103-104. 